\title{
A review and additional post-hoc analyses of the incidence and impact of constipation observed in darifenacin clinical trials
}

This article was published in the following Dove Press journal:

Drug, Healthcare and Patient Safety

26 September 2012

Number of times this article has been viewed

\author{
Jan Tack' \\ Jean-Jacques Wyndaele ${ }^{2}$ \\ Greg Ligozio ${ }^{3}$ \\ Mathias Egermark ${ }^{4}$ \\ 'University of Leuven, \\ Gastroenterology Section, \\ Leuven, ${ }^{2}$ University of Antwerp, \\ Department of Urology, Antwerp, \\ Belgium; ${ }^{3}$ Novartis Pharmaceuticals \\ Corporation, NJ, USA; ${ }^{4}$ Roche \\ Diagnostics Scandinavia AB, Bromma, \\ Sweden and formerly of Novartis \\ Pharma AG, Basel, Switzerland
}

Background: Constipation is a common side effect of antimuscarinic treatment for overactive bladder $(\mathrm{OAB})$. This review evaluates the incidence and impact of constipation on the lives of patients with OAB being treated with darifenacin.

Methods: Constipation data from published Phase III and Phase IIIb/IV darifenacin studies were reviewed and analyzed. Over 4000 patients with OAB (aged $18-89$ years; $\geq 80 \%$ female) enrolled in nine studies (three Phase III [data from these fixed-dose studies were pooled and provide the primary focus for this review], three Phase IIIb, and three Phase IV). The impact of constipation was assessed by discontinuations, use of concomitant laxatives, patient-reported perception of treatment, and a bowel habit questionnaire.

Results: In the pooled Phase III trials, 14.8\% (50/337) of patients on darifenacin $7.5 \mathrm{mg} /$ day and $21.3 \%$ (71/334) on $15 \mathrm{mg} /$ day experienced constipation compared with $12.6 \%(28 / 223)$ and $6.2 \%(24 / 388)$ with tolterodine and placebo, respectively. In addition, a few patients discontinued treatment due to constipation $(0.6 \%$ [2/337], 1.2\% [4/334], 1.8\% [4/223], and $0.3 \%$ [1/388] in the darifenacin $7.5 \mathrm{mg}$ /day or $15 \mathrm{mg} /$ day, tolterodine, and placebo groups, respectively), or required concomitant laxatives (3.3\% [11/337], 6.6\% [22/334], 7.2\% [16/223], and 1.5\% [6/388] in the darifenacin $7.5 \mathrm{mg}$ /day or $15 \mathrm{mg}$ /day, tolterodine, and placebo groups, respectively). Patient-reported perception of treatment quality was observed to be similar between patients who experienced constipation and those who did not. During the long-term extension study, a bowel habit questionnaire showed only small numerical changes over time in frequency of bowel movements, straining to empty bowels, or number of days with hard stools.

Conclusion: While constipation associated with darifenacin was reported in $\leq 21 \%$ of the patient population, it only led to concomitant laxative use in approximately one-third of these patients and a low incidence of treatment discontinuation. These data suggest that constipation did not impact patient perception of treatment quality.

Keywords: antimuscarinics, tolerability, overactive bladder

\section{Introduction}

Overactive bladder (OAB) is a chronic condition characterized by urinary urgency, with or without urge incontinence, usually with increased frequency of micturition and nocturia, and in the absence of urinary tract infection or other obvious pathology. ${ }^{1}$ It is estimated that $\mathrm{OAB}$ affects approximately $11 \%$ of adults in Europe and Canada. ${ }^{2}$ The condition is associated with considerable impairment of many aspects of patients' quality of life, such as sleep and mental health, ${ }^{3,4}$ while $\geq 65 \%$ of sufferers with OAB report a negative impact on daily living. ${ }^{5}$ The total economic costs of OAB are estimated to be approximately US\$12 billion in the $\mathrm{USA}^{6}$ and $€ 4$ billion in Europe. ${ }^{7}$
Correspondence: Jan Tack University of Leuven, Gastroenterology Section, Leuven, Belgium, BE-3000

Tel +32 16344225

Fax +3216344419

Email jan.tack@med.kuleuven.ac.be 
Antimuscarinic drugs remain a first-line pharmacologic treatment option for OAB. Meta-analyses have demonstrated that licensed antimuscarinic treatments such as tolterodine, darifenacin, oxybutynin, trospium, solifenacin, fesoterodine, and propiverine reduce incontinence episodes (IEs) and other OAB symptoms compared with placebo. ${ }^{8-10}$ In a pooled analysis of three Phase III studies, darifenacin provided statistically significant reductions in the frequency of IEs, micturitions, urgency episodes, and leaks requiring change of pad or clothing compared with placebo (all $P<0.001$ ). ${ }^{11}$ Darifenacin is available in two doses, $7.5 \mathrm{mg} /$ day and $15 \mathrm{mg} /$ day, with the higher dose being statistically significantly more effective $(P \leq 0.002) .{ }^{11}$ This ability to uptitrate therapeutic dose can benefit patients with the higher dose of darifenacin, providing further improvements in many OAB symptoms compared with lower doses. ${ }^{12-15}$

While similar in their mechanism of action, available antimuscarinics vary in their relative affinity for muscarinic receptor subtypes. ${ }^{16,17}$ The five muscarinic receptor subtypes are distributed throughout the body and mediate different autonomic effects. ${ }^{18}$ Although the precise functions and distribution of each of the muscarinic receptors remains to be fully clarified, there is evidence to show that: $M_{1}$ receptors are predominantly located in the brain and salivary glands and are involved with cognitive function and saliva secretion; $\mathrm{M}_{2}$ receptors are located in the heart and smooth muscle and are involved with regulation of cardiac function and muscle contraction; and $\mathrm{M}_{3}$ receptors are predominantly located in the bladder and smooth muscle and are involved with muscle contractions. ${ }^{19}$

OAB results from abnormal, involuntary detrusor muscle contractions, which occur during bladder filling. ${ }^{20} \mathrm{M}_{3}$ receptors are thought to be primarily responsible for detrusor contraction, with limited evidence that $\mathrm{M}_{2}$ may play a role in bladder contractions, ${ }^{19,21}$ thus the $\mathrm{M}_{3}$ receptor subtype may be considered an important target in the pharmacotherapy of OAB. Amongst available antimuscarinics, darifenacin has the highest relative affinity for the $\mathrm{M}_{3}$ receptor over other receptor subtypes (including $\mathrm{M}_{1}$ and $\mathrm{M}_{2}$ ) compared with other commonly prescribed antimuscarinics, including oxybutynin (selective for $\mathrm{M}_{3}$ over $\mathrm{M}_{2}$ ), propiverine (nonselective), solifenacin (selective for $\mathrm{M}_{3}$ over $\mathrm{M}_{1}$ and $\mathrm{M}_{2}$ ), and tolterodine (nonselective). ${ }^{16,17}$

Muscarinic receptors are also present in the gastrointestinal tract smooth muscle in similar proportions to that observed in the bladder 22,23 and it is currently thought that $\mathrm{M}_{3}$ receptors are primarily responsible for gastrointestinal muscle contractions. ${ }^{24-26}$ As a result, antagonism of $\mathrm{M}_{3}$ receptors may slow colonic transit and consequently lead to altered bowel habits and symptoms of constipation. However, in mice lacking the $\mathrm{M}_{3}$ receptor, small but significant contractions in the ileum remained, suggesting that $\mathrm{M}_{2}$ receptors may play a larger role in gut motility than thought previously. ${ }^{27}$

Constipation, defined as a functional bowel disorder that presents as persistently difficult, infrequent, or seemingly incomplete defecation, which does not meet irritable bowel syndrome criteria, ${ }^{28}$ is highly prevalent in the general population. A random mail survey of the general public in Minnesota (aged between 20 and 94 years) in 1998 and repeated in 2003 was used to calculate a cumulative incidence of chronic constipation of $17.4 \%(112 / 645) .{ }^{29}$ Furthermore, chronic constipation was associated with age and gender $(P<0.01)$. The authors from this population-based study postulated that one in six people will develop chronic constipation over a decade.

Together with dry mouth, constipation is the most common adverse event (AE) observed with currently available antimuscarinic drugs. ${ }^{30-33}$ However, unlike dry mouth, constipation associated with antimuscarinic treatment has not been systematically and thoroughly reviewed. ${ }^{34}$ In otherwise healthy patients with symptoms of OAB, constipation has been reported with both immediate-release (twice daily) and extended-release (once daily) formulations of tolterodine $(6.8 \%$ [35/512] and 5.9\% [30/505] of patients, respectively, compared with $4.3 \%$ [22/507] of patients receiving placebo). ${ }^{33}$ Pooled analysis of two Phase III studies with transdermal oxybutynin reported an incidence of constipation in $2.1 \%(5 / 242)$ of patients with urge or mixed urinary incontinence receiving the study drug and $2.0 \%$ $(5 / 245)$ of those receiving placebo. ${ }^{35}$ Similarly, an incidence of constipation of $4.2 \%(10 / 249)$ and $12.2 \%(50 / 409)$ in patients with $\mathrm{OAB}$ but no incontinence receiving solifenacin $5 \mathrm{mg} /$ day and $10 \mathrm{mg} /$ day, respectively, compared with $1.3 \%(5 / 390)$ in the placebo group was reported in a pooled analysis of four Phase III studies. ${ }^{36}$ In a comparator study of solifenacin and tolterodine in patients with OAB, solifenacin $5 \mathrm{mg}$ and $10 \mathrm{mg}$ once daily were associated with a greater incidence of constipation (7.2\% [20/279] and 7.8\% [21/268], respectively) than tolterodine $2 \mathrm{mg}$ twice daily $(2.6 \%[7 / 203]) .{ }^{37}$ Furthermore, the incidence of constipation with fesoterodine was $6.0 \%(34 / 566)$ with the $8 \mathrm{mg}$ once daily dose and $4.2 \%(23 / 554)$ with the $4 \mathrm{mg}$ once daily dose and $2.0 \%(11 / 554)$ with placebo in a pooled analysis of two randomized controlled trials in patients with urgency or urge incontinence. ${ }^{13}$ In addition, 9.4\% (28/298) of patients with $\mathrm{OAB}$ receiving trospium $60 \mathrm{mg}$ once daily experienced 
constipation compared with $1.3 \%$ (4/303) of patients in the placebo group. ${ }^{38}$

A recent meta-analysis highlighted that patients receiving antimuscarinics for $\mathrm{OAB}$ are significantly more likely to experience constipation than those receiving placebo, ${ }^{34}$ however, the incidence and impact of constipation on the lives of patients with $\mathrm{OAB}$ being treated with antimuscarinics has yet to be evaluated. This review will primarily report on the incidence and impact of constipation in patients receiving darifenacin in published Phase III and Phase IV clinical studies (completed between 2002 and 2007) ${ }^{39-46}$ Data from patients receiving the licensed darifenacin doses available in clinical practice $(7.5 \mathrm{mg} /$ day and $15 \mathrm{mg} /$ day $)$ were evaluated, with the focus on data from a pooled analysis of three fixeddose Phase III studies of very similar design. ${ }^{11}$ Additional data were obtained from three Phase IIIb studies, ${ }^{14,42,45}$ including a dose-titration study ${ }^{14}$ and a long-term (2-year) study, ${ }^{42}$ as well as three Phase IV post-approval studies ${ }^{43,44,46}$ in patients with $\mathrm{OAB}$. Inclusion of these studies in this review provided a large dataset that adds greater numerical strength to the evaluation on the impact of constipation, associated with darifenacin treatment, on the lives of patients with $\mathrm{OAB}$. Furthermore, additional analyses on existing databases from these studies were performed; these are distinguishable from the published analyses that have been cited. These constipation data were not included in the original publications but are reported here. Key details of the included studies and incidence of constipation are given in Table 1. ${ }^{14,39-46}$

\section{Pooled analysis of Phase III studies}

The primary outcome data (efficacy) from the pooled analysis of three randomized controlled trials have been reported elsewhere, along with the consistent methodology, inclusion/exclusion criteria, efficacy, and safety assessments that allowed the data from three individual studies to be pooled. ${ }^{11}$ In each study, patients aged $\geq 18$ years entered a 2 -week washout period (if receiving prohibited medication, such as agents with significant anticholinergic effect [eg, anticholinergics and tricyclic antidepressants] and drugs that cause significant constipation prior to the start of the study) and a 2 -week treatment-free or placebo run-in period. Upon completion of the placebo run-in period, patients were randomized to 12 weeks' double-blind treatment with study medication (placebo or fixed-doses of darifenacin $7.5 \mathrm{mg}$ or $15 \mathrm{mg}$ once daily). One study also included a tolterodine treatment group, who received $4 \mathrm{mg}$ /day ( $2 \mathrm{mg}$ twice daily). The main inclusion criteria were: men and women aged $\geq 18$ years with symptoms of $\mathrm{OAB}$ for $\geq 6$ months; 5-50 IEs/week; an average of $\geq 8$ micturitions/day; and at least one urgency episode/day. For all studies, patients with severe constipation $(<3$ defecations a week) were excluded. Tolerability and safety were evaluated from withdrawal rates and AEs. AEs were reported by the patients during treatment and 14 days after the end of treatment, recorded by the investigator and coded in the study databases using coding symbols for a thesaurus of adverse reaction terms (COSTART) criteria. ${ }^{47} \mathrm{AEs}$ were tabulated by body system, eg, digestive system, nervous system, and body as a whole. Some of the terms coded as constipation were "difficulty with defecation," "feeling of incomplete evacuation," and "increased hard stools." It was also recorded if additional drug administration, such as laxatives or stool softeners, were required. In order to assess the severity of constipation by objective outcome measures, the common toxicity criteria (CTC) grading was retrospectively applied to the constipation data from the Phase III studies for all treatment groups and then to the pooled data. ${ }^{47}$ The severity of constipation was scored from one to five and graded as mild, moderate or severe, respectively. ${ }^{47}$

Baseline demographics were comparable between treatment groups in each study and are covered in detail elsewhere. ${ }^{11}$ In brief, 1059 patients were included in the pooled data analysis, most patients were female ( $85 \%$ ), ages ranged from 19 to 88 years (mean age 56-57) and $22 \%$ had previously received drug therapy for their OAB symptoms in the 3 months before study inclusion. ${ }^{11}$ Furthermore, $>4 \%$ of patients in each treatment group were receiving laxatives at baseline.

The overall incidence of constipation as reported by patients in the pooled Phase III studies was $18 \%(121 / 671) .{ }^{11}$ Data from the individual Phase III studies, including the comparator study with tolterodine, are presented in Table $1 .{ }^{39-41}$ From the analysis of pooled data, a higher incidence of constipation was reported with higher doses of darifenacin, $14.8 \%$ for $7.5 \mathrm{mg}$ /day compared with $21.3 \%$ for $15 \mathrm{mg} /$ day (Figure 1). However, the proportion of patients who experienced constipation while receiving tolterodine or darifenacin $7.5 \mathrm{mg} /$ day were $12.6 \%$ and $14.8 \%$, respectively (Figure 1 ). In addition, the incidence of constipation was higher in older patients receiving darifenacin and tolterodine. Overall, 18.6\% (18/97) of patients aged $\geq 65$ years experienced constipation while receiving darifenacin $7.5 \mathrm{mg} /$ day $^{48}$ compared with $13.3 \%$ of patients aged 18-64 years. Differences in the incidence of constipation in each age group were observed in patients receiving darifenacin $15 \mathrm{mg} /$ day $(20.1 \%$ [45/224] in patients aged $18-64$ years and $23.6 \%[26 / 110]$ in patients aged $\geq 65$ years, ${ }^{48}$ respectively) and those receiving tolterodine $4 \mathrm{mg} /$ day (11.8\% [16/136] and 13.8\% [12/87], respectively). 


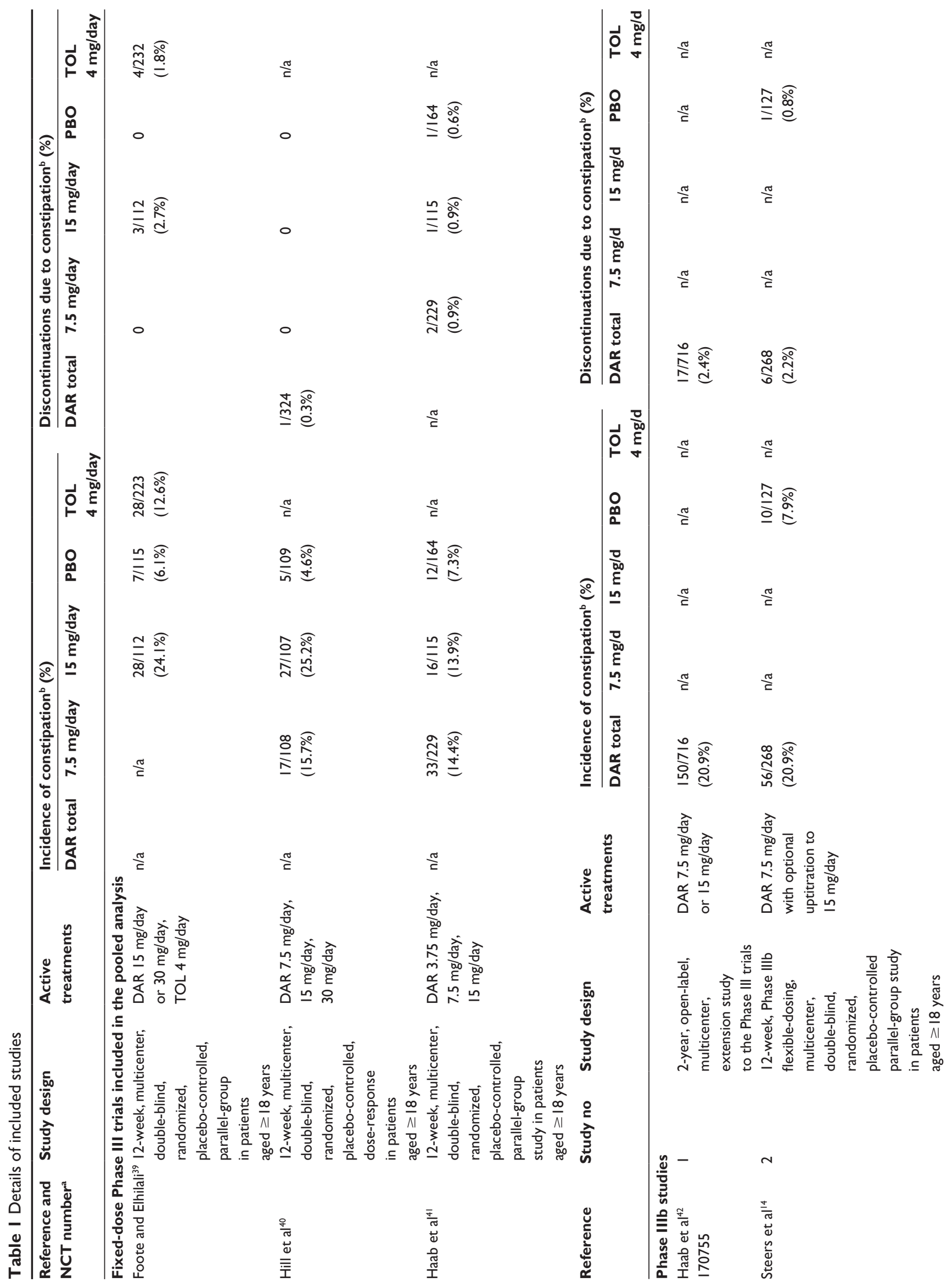


$\stackrel{5}{\varepsilon}$

농

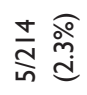

Еี

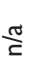

$\stackrel{2}{\varepsilon}$

空

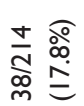

$\stackrel{2}{\Sigma}$

$\stackrel{\frac{1}{2}}{2}$

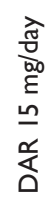

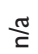

$\stackrel{\square}{\varepsilon}$

$\stackrel{\pi}{E}$

$\stackrel{2}{E}$

竞

$\stackrel{2}{\Xi}$

$\stackrel{20}{ \pm}$

$\stackrel{0}{\varepsilon}$

$\stackrel{\Re}{E}$

旁离

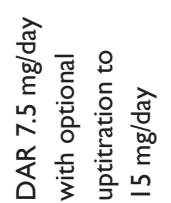

$\stackrel{2}{\underline{E}}$

$\stackrel{20}{\pi}$

$\stackrel{2}{2}$

$\stackrel{2}{E}$

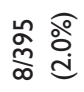

ำ

$\stackrel{\mathbb{E}}{E}$

$\stackrel{2}{\Sigma}$

$\stackrel{\mathscr{E}}{E}$

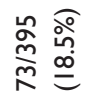

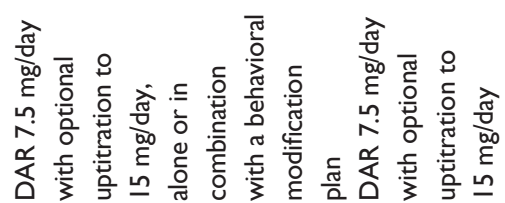

ะี

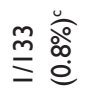

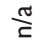

$\stackrel{\Xi}{E}$

ลั

$\frac{2}{E}$

$\stackrel{m}{=} \underset{\substack{\infty \\ \infty}}{\stackrel{\infty}{\infty}}$

$\stackrel{5}{E}$

$\stackrel{็}{E}$

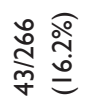
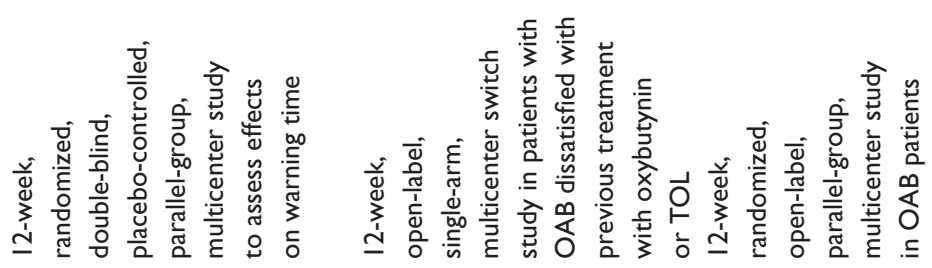

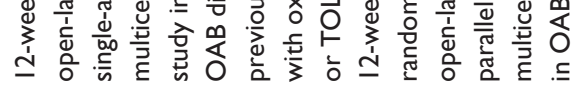
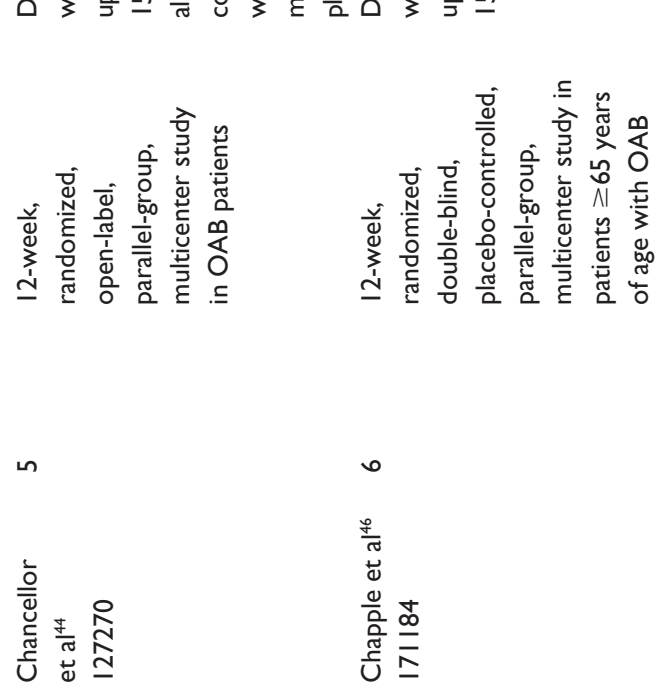

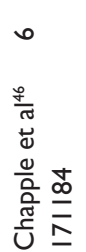




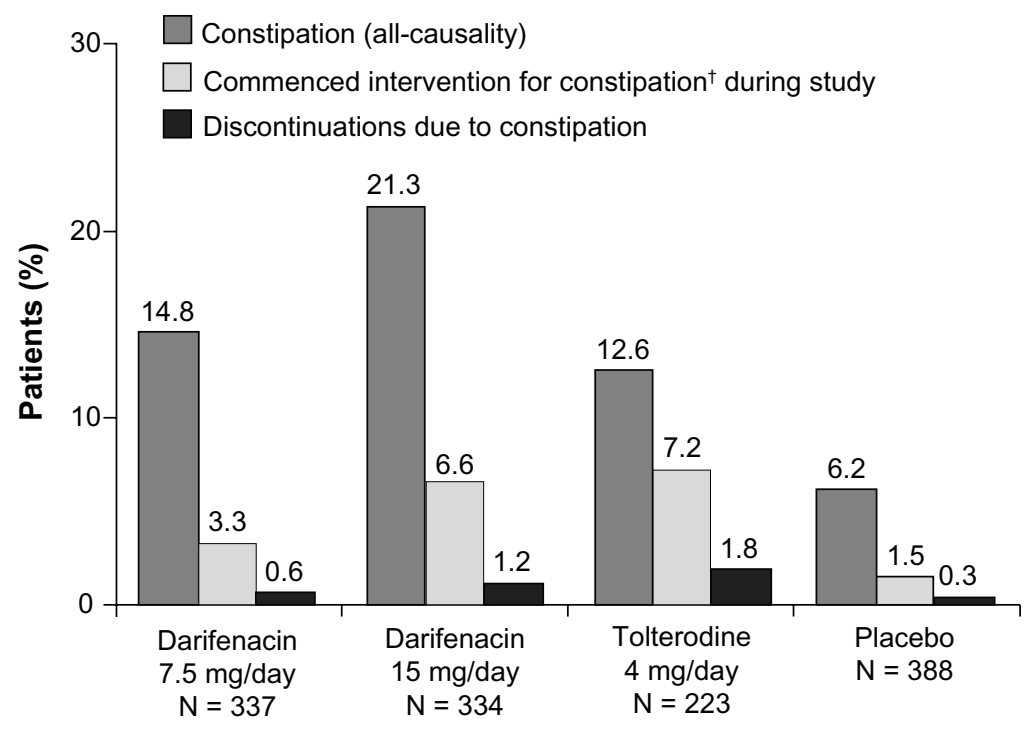

Figure I Incidences of constipation (all-causality), new-onset use of constipation remedies and discontinuations resulting from constipation during 12 weeks' treatment with darifenacin $7.5 \mathrm{mg} /$ day or $15 \mathrm{mg} /$ day, tolterodine $4 \mathrm{mg} /$ day or placebo in patients with overactive bladder.

Note: 'Laxatives, stool softeners or fiber supplements.

\section{Impact of constipation in the pooled analysis of Phase III studies}

In this pooled analysis, most episodes of constipation $(56.6 \%$ [98/173]) were graded as mild in severity (Table 2). Only $1.6 \%(11 / 671)$ of patients receiving darifenacin $7.5 \mathrm{mg} /$ day or $15 \mathrm{mg} /$ day experienced constipation classified as severe. A similar proportion (1.8\% [4/223]) of patients receiving tolterodine experienced severe constipation (Table 2).

The majority of constipation cases occurred within 2 weeks of treatment initiation (56.0\% [28/50]) of patients who reported constipation while receiving darifenacin $7.5 \mathrm{mg}$ and $80.3 \%$ [57/71] of those receiving darifenacin $15 \mathrm{mg}$ compared with $53.6 \%$ [15/28] of tolterodine patients and 62.5\% [15/24] of patients in the placebo group; (Figure 2). The median time-toonset of constipation was 14 days in the darifenacin $7.5 \mathrm{mg} /$ day group, 6 days in the $15 \mathrm{mg} /$ day group, 13.5 days in the tolterodine group, and 7 days in the placebo group.

In the pooled analysis of Phase III studies, few patients discontinued treatment due to constipation (Figure 1): $0.6 \%(2 / 337)$ of patients receiving darifenacin $7.5 \mathrm{mg} /$ day
( $4 \%$ of patients reporting constipation in the $7.5 \mathrm{mg}$ dose group $[\mathrm{N}=2 / 50]) ; 1.2 \%(4 / 334)$ of patients receiving darifenacin $15 \mathrm{mg} /$ day (5.6\% of patients reporting constipation in the $15 \mathrm{mg}$ dose group $[\mathrm{N}=4 / 71])$; and $1.8 \%$ (4/223) of patients receiving tolterodine $(14.3 \%$ of patients reporting constipation in this group $[\mathrm{N}=4 / 28])$. In addition, $0.3 \%(1 / 388)$ of patients in the placebo group ( $4.2 \%$ of patients reporting constipation in this group $[\mathrm{N}=1 / 24]$ ) discontinued due to constipation.

Overall, there was a low rate of medical intervention for constipation during the studies (Figure 1 and Table 3). Of those patients receiving darifenacin $7.5 \mathrm{mg} /$ day, $5.9 \%$ $(20 / 337)$ were taking laxatives during the study, including $22 \%(11 / 50)$ of all patients reporting constipation and $3.1 \%(9 / 287)$ of patients not reporting constipation. In the $15 \mathrm{mg} /$ day dose group, $9.6 \%$ (32/334) of patients were taking laxatives during the study, including $31 \%(22 / 71)$ of patients reporting constipation in this dose group and 3.8\% (10/263) who did not report constipation. Furthermore, 6.2\% [24/388] of patients receiving placebo used laxatives (including 25\% [6/24] of patients reporting constipation) and $10.3 \%$ [23/223]

Table 2 Incidence of all-causality constipation in fixed-dose Phase III studies in OAB patients

\begin{tabular}{lllll}
\hline Constipation severity & Darifenacin $\mathbf{7 . 5} \mathbf{~ m g / d a y}$ & Darifenacin I5 $\mathbf{~ m g / d}$ & Tolterodine $\mathbf{4}$ mg/d & Placebo \\
& $\mathbf{N}=\mathbf{3 3 7}$ & $\mathbf{N}=\mathbf{3 3 4}$ & $\mathbf{N}=\mathbf{2 2 3}$ & $\mathbf{N}=\mathbf{3 8 8}$ \\
\hline Mild, N (\%) & $29(8.6)$ & $39(11.7)$ & $15(6.7)$ & $15(3.9)$ \\
Moderate, N (\%) & $19(5.6)$ & $23(6.9)$ & $9(4.0)$ & $7(1.8)$ \\
Severe, N (\%) & $2(0.6)$ & $9(2.7)$ & $4(1.8)$ & $2(0.5)$ \\
Total & $50(14.8)$ & $71(21.3)$ & $28(12.6)$ & $24(6.2)$ \\
\hline
\end{tabular}

Abbreviation: $\mathrm{OAB}$, overactive bladder. 
Total constipation reports over 12 weeks (\%)

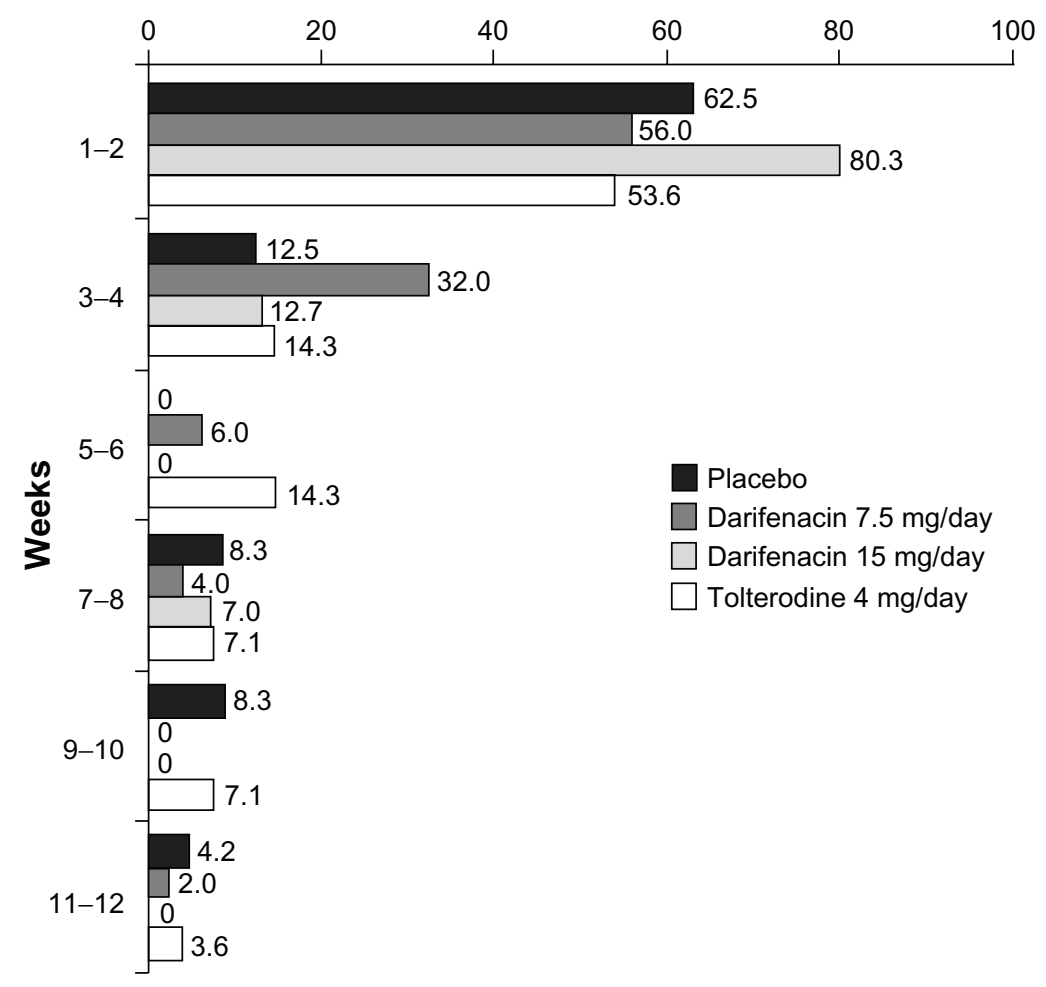

Figure 2 Proportion of new cases of all-causality constipation reported at different time points during treatment with darifenacin $7.5 \mathrm{mg} /$ day or $15 \mathrm{mg} /$ day, tolterodine $4 \mathrm{mg} /$ day or placebo.

of patients receiving tolterodine (including 57\% [16/28] reporting constipation). The use of concomitant laxatives in patients not reporting constipation may indicate that some patients were taking laxatives prophylactically (Table 3).

\section{Impact of constipation on patient- reported outcomes in Phase III trials}

The patient perception of quality of treatment (PPQT) was assessed in the three pooled Phase III trials by three questions given at study end (Week 12):
1. "Overall, how satisfied are you with the drug you received over the past 12 weeks?", scored on a scale from 1 to 5 ("Extremely satisfied" to "Extremely dissatisfied")

2. "Overall, do you prefer the drug you received on this clinical trial to your previous treatment?", scored on a scale from 1 to 5 ("Yes, I definitely prefer the drug I am receiving now" to "No, I definitely prefer my previous treatment")

3. "In the future, would you be willing to use the same drug that you received on this clinical trial?", scored

Table 3 Concomitant laxative use in fixed-dose Phase III studies in OAB patients

\begin{tabular}{|c|c|c|c|c|}
\hline & Darifenacin $7.5 \mathrm{mg} / \mathrm{day}$ & Darifenacin 15 mg/day & Tolterodine $4 \mathrm{mg} / \mathrm{day}$ & Placebo \\
\hline \multicolumn{5}{|l|}{ All patients } \\
\hline $\mathrm{N}$ & 337 & 334 & 223 & 388 \\
\hline Using laxatives at baseline (\%) & $9(2.7)$ & $13(3.9)$ & $8(3.6)$ & $15(3.9)$ \\
\hline Using laxatives during trial (\%) & $20(5.9)$ & $32(9.6)$ & $23(10.3)$ & $24(6.2)$ \\
\hline \multicolumn{5}{|l|}{ Patients with constipation } \\
\hline $\mathrm{N}(\%)$ & $50(14.8)$ & $7 \mid(2 I .3)$ & $28(12.6)$ & $24(6.2)$ \\
\hline Using laxatives at baseline (\%) & $2(4.0)$ & $4(5.6)$ & $\mathrm{I}(3.6)$ & $0(0)$ \\
\hline Using laxatives during trial (\%) & II (22.0) & $22(31.0)$ & $16(57.1)$ & $6(25.0)$ \\
\hline \multicolumn{5}{|l|}{ Patients with no constipation } \\
\hline $\mathrm{N}(\%)$ & $287(85.2)$ & $263(78.7)$ & $195(87.4)$ & $364(93.8)$ \\
\hline Using laxatives at baseline (\%) & $7(2.4)$ & $9(3.4)$ & $7(3.6)$ & $15(4.1)$ \\
\hline Using laxatives during trial (\%) & $9(3.1)$ & $10(3.8)$ & $7(3.6)$ & $18(4.9)$ \\
\hline
\end{tabular}

Abbreviation: $O A B$, overactive bladder. 
on a scale from 1 to 5 ("Yes, I would definitely want to use the same drug" to "No, I definitely would not want to use the same drug").

Of patients receiving darifenacin 7.5/15 mg/day, 59.4\% $(63 / 106)$ and $54.7 \%(267 / 488)$ of patients with and without constipation, respectively, reported satisfaction with treatment; $68.6 \%(72 / 105)$ and $68.1 \%(329 / 483)$ of patients, respectively, reported their preference for darifenacin over previous therapy; and 64.8\% (68/105) and 65.8\% (318/483) of patients, respectively, were willing to re-use darifenacin. Overall, PPQT was numerically comparable between patients who experienced constipation and those that did not in the pooled analysis of Phase III trials (for individual treatment groups please see Figure 3).

\section{Constipation with long-term (2-year) darifenacin treatment}

A total of 716 patients with OAB (mean age 57.3 years; $85.1 \%$ women) entered a 2 -year, open-label, extension study (Table 1, study 1$)^{42}$ from two Phase III trials with similar inclusion criteria, one fixed-dose ${ }^{41}$ and one flexible-dosing. ${ }^{14}$ In addition to reporting AEs, all patients completed a bowel habit questionnaire (Table 4A) at the start of this extension study and at completion. This questionnaire assessed whether and how patients' bowel habits changed following long-term treatment with darifenacin.

At the end of the long-term study, the incidence of allcausality constipation was $20.9 \%(150 / 716)$ but few patients (2.4\% [17/716]) discontinued treatment as a consequence of constipation. ${ }^{42}$ Overall, 5.6\% (40/716) of patients initiated use of fiber supplements, stool softeners or laxatives during this extension study. ${ }^{42}$ Differences observed in bowel habit parameters, such as frequency of bowel motions, stool consistency, straining and feeling of incomplete evacuation, from baseline (end of the Phase III study) compared with end of extension study (Figure 4A) were numerically low and bowel habits were shown not to affect daily life.

\section{Additional Phase IIIb OAB studies}

In addition to the fixed-dose Phase III trials included in the pooled analysis, two 12-week Phase IIIb studies in patients with OAB were analyzed (Table 1 , studies 2 and 3). ${ }^{14,45}$ In a flexible-dosing study (with similar inclusion criteria to the fixed-dose studies), 395 patients with OAB (mean age 58 years, $84 \%$ female) received darifenacin $7.5 \mathrm{mg} /$ day for 2 weeks with an optional uptitration to $15 \mathrm{mg} /$ day. ${ }^{14}$ The overall incidence of constipation was $20.9 \%(56 / 268)$ compared with $7.9 \%(10 / 127)$ in the placebo group (Table 1 ,
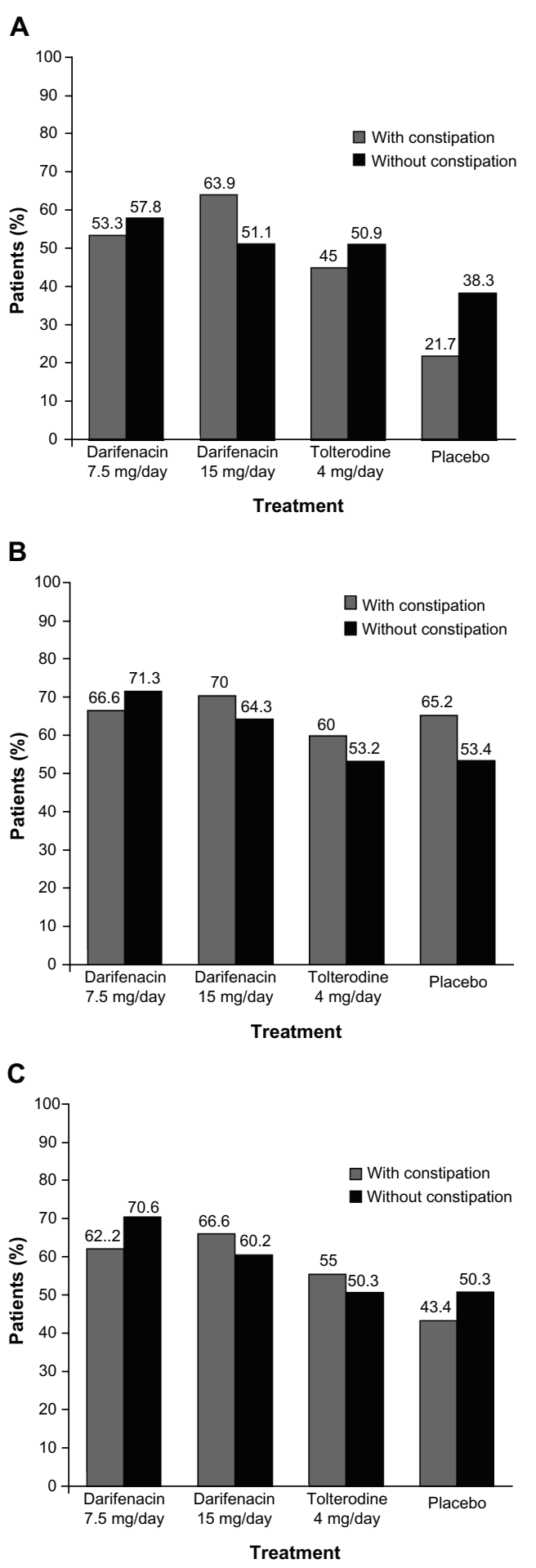

Figure 3 Patient perception of quality of treatment in fixed-dose Phase III studies in overactive bladder patients. (A) Patient satisfaction with drug; (B) Patient preference for study drug over previous therapy; (C) patient willingness to re-use study drug.

study 2). ${ }^{14}$ Constipation was considered by the investigators to be severe in $1.5 \%(4 / 268)$ and $0.8 \%(1 / 127)$ of darifenacintreated and placebo-treated patients, respectively. Six patients $(2.2 \%)$ discontinued darifenacin treatment due to constipation compared with one patient $(0.8 \%)$ in the placebo group. 
Table 4 Bowel habit questionnaires

(A) Used in the long-term extension study (all questions refer to the $\mathbf{2}$ weeks preceding the visit)

On how many days did you open your bowels?

On days you opened your bowels how many times did you go to the toilet?

How many days were your bowel movements hard and/or lumpy?

How many days did you have to strain to open bowels?

How many days did you feel your bowels were not fully emptied

after a visit to the lavatory?

How many days did you feel your bowel habits affected your life?

If your bowel habits affected your life, overall how much was

this effect?

(B) Phase IV study in patients $\geq \mathbf{6 5}$ years of age

QI: Did you have to strain to move your bowels?

No

Yes

Q2: If yes, how much straining did you have to do? (if no, skip question) Acceptable straining

Too much straining

Q3: What was the usual consistency of your bowel movements?

(choose one)

Separate hard lumps, like nuts (hard to pass)

Sausage shaped but lumpy

Like a sausage but with cracks on its surface

Like a sausage or snake, smooth and soft

Soft blobs with clear cut edges (passed easily)

Fluffy pieces with ragged edge, a mushy stool

Watery, no solid pieces

Q4: How often do you have bowel movements?

Less often

Unchanged

More often

Q5: Do you still: (check one)

Move your bowels every day

Move your bowels every other day

Move your bowels 2 or less times per week

Other

Q6: Have you had to strain to move your bowels?

No

Yes

Q7: If yes, how much straining have you had to do?

(if no, skip question)

Acceptable straining

Too much straining

Q8: What has been the usual consistency of your bowel movements? (choose one)

Separate hard lumps, like nuts (hard to pass)

Sausage shaped but lumpy

Like a sausage but with cracks on its surface

Like a sausage or snake, smooth and soft

Soft blobs with clear cut edges (passed easily)

Fluffy pieces with ragged edge, a mushy stool

Watery, no solid pieces

Q9: Has the change in your bowel habits affected or interfered

with your life in general? (check one)

Yes, in a bad way

Not at all

Yes, in a good way

(Continued)
Table 4 (Continued)

QI0: How much has the change in your bowel habits affected or interfered with your life in general? (check one)

Very little

Moderately

Quite a lot

Very much

Laxative use was initiated by $11.2 \%(30 / 268)$ and $7.9 \%$ $(10 / 127)$ of patients in the darifenacin and placebo groups, respectively.

A numerically similar incidence of constipation was reported in a randomized, double-blind, placebo-controlled study with darifenacin $15 \mathrm{mg} /$ day. $^{45}$ In this study of 439 patients with OAB (mean age 59.1 years; $87 \%$ female), constipation was reported by $17.8 \%(38 / 214)$ and $4.9 \%$ $(11 / 225)$ of patients receiving darifenacin and placebo, respectively (Table 1 , study 3 ). ${ }^{45}$ The majority of cases of constipation were considered by investigators to be mild or moderate in severity. For both the darifenacin and placebo dose groups, only one case of severe constipation was reported in each. Five patients $(2.3 \%)$ receiving darifenacin discontinued treatment due to constipation compared with none of the patients receiving placebo.

\section{Post-approval (Phase IV) OAB studies}

Data from three 12-week Phase IV studies conducted to further characterize the efficacy and tolerability of darifenacin in patients with $\mathrm{OAB}$ were included in this current analysis of constipation. ${ }^{43,44,46}$ One open-label study (Table 1, study 4) recruited 497 patients with OAB (mean age 60.9 years; $84 \%$ female) that were dissatisfied with previous extended-release antimuscarinic treatment (oxybutynin or tolterodine) ${ }^{43}$ After a 2-3 week prescreening/washout period during which prohibited medications were discontinued, patients then received darifenacin $7.5 \mathrm{mg} /$ day for the first 2 weeks with voluntary uptitration to darifenacin $15 \mathrm{mg} /$ day. ${ }^{43}$ An overall incidence of constipation of $14.1 \%$ (70/497) with darifenacin was reported. In patients treated previously with oxybutynin or tolterodine an incidence of $11.0 \%$ (24/218) and 16.5\% (46/279), respectively was observed. ${ }^{43}$ Four patients $(0.8 \%)$ discontinued treatment due to constipation.

Another open-label study (Table 1, study 5; $\mathrm{N}=395$ ) randomized patients to either darifenacin $7.5 \mathrm{mg}$ /day (with optional uptitration to $15 \mathrm{mg} /$ day) alone or in combination with a behavioral modification plan, which included pelvic muscle exercises and urgency control techniques. ${ }^{44}$ 
A

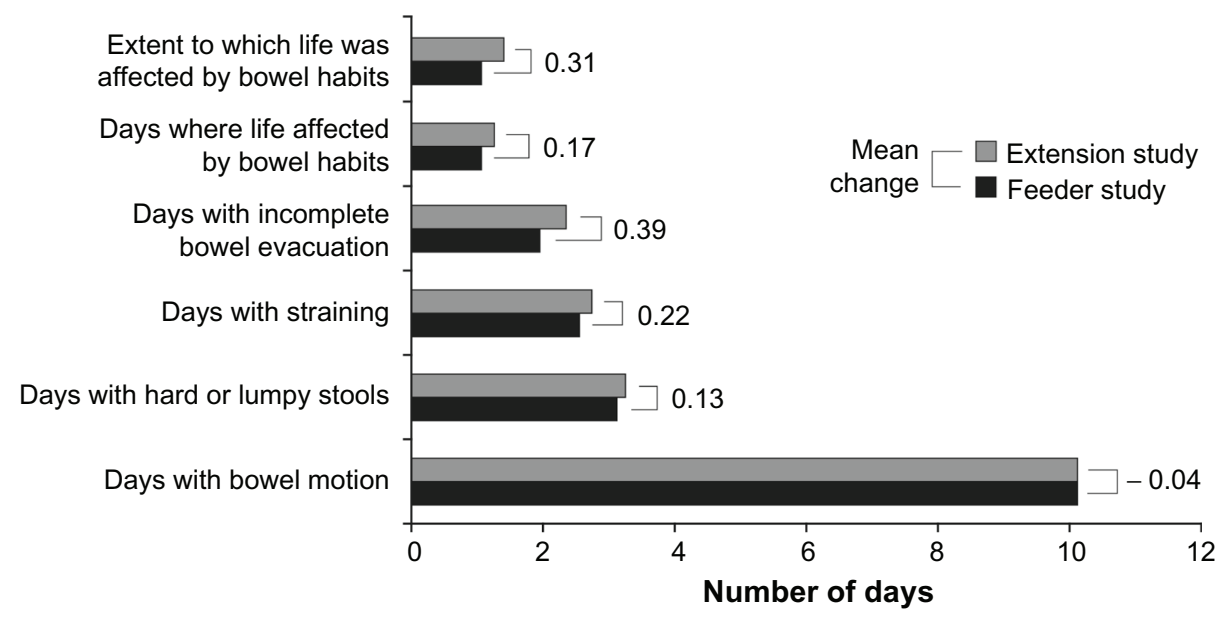

B

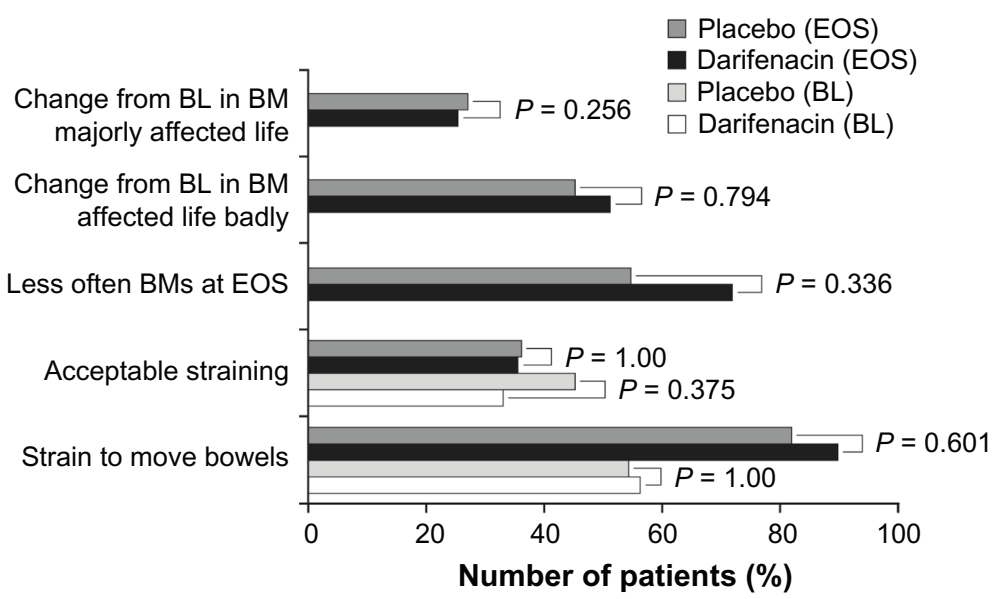

Figure 4 (A) Summary of bowel habit questionnaire responses in patients in a long-term 2-year study; (B) Summary of bowel habit questionnaire responses in patients aged $\geq 65$ years; results relate to the last 2 weeks of treatment.

Note: "Feeder study" refers to last visit or last observation carried forward from the feeder study.

Abbreviations: BL, baseline; BM, bowel movements; EOS, end of study.

The overall incidence of constipation was $18.5 \%(73 / 395) .{ }^{44}$ Eight patients $\left(2.0 \%{ }^{* 44}\right.$ two patients receiving darifenacin alone and six receiving darifenacin plus behavioral modification plan) discontinued treatment due to constipation.

A randomized, double-blind, placebo-controlled study was conducted in $\mathrm{OAB}$ patients over the age of 65 years (Table 1, study 6; $\mathrm{N}=399$ ). ${ }^{46}$ Patients were randomized to darifenacin $7.5 \mathrm{mg} /$ day (with optional uptitration to $15 \mathrm{mg} /$ day, $\mathrm{N}=266)$ or placebo $(\mathrm{N}=133)$. Of the 41 (15.4\%) elderly patients (aged $\geq 65$ years) receiving darifenacin who reported constipation, 39 completed the bowel habit questionnaire (Table 4B). Using the data from this questionnaire, the proportions of patients on each treatment were compared statistically using Fisher's exact test. In total, $89.7 \%$ (35/39) patients receiving darifenacin indicated that they needed to strain to empty their bowels (Figure 4B); which is a similar proportion to that observed in patients receiving placebo $(81.8 \%$ [9/11]; $P=0.601)$. However, $35.9 \%(14 / 39)$ of patients with constipation while receiving darifenacin reported that the amount of straining required was acceptable ( $P=1.000$ compared with placebo, $36.4 \%$ [4/11]). While the majority of patients, $71.8 \%$ [28/39], reported a reduction in the frequency of their bowel movements, there was no significant difference in comparison with placebo $(54.5 \%[6 / 11] ; P=0.336)$. There was also no significant difference in the number of patients reporting that constipation had affected their life badly $(51.3 \%$ [20/39] of patients receiving darifenacin compared with $45.5 \%[5 / 11]$ of patients receiving placebo; $P=0.794)$. The majority of patients in both the darifenacin $(69.2 \%$ [27/39]) and placebo (72.7\% [8/11]) groups felt that the change in their bowel habits had affected their lives "very little" or "moderately." There was no significant difference between groups $(P=0.256)$. 


\section{Discussion}

Antimuscarinic treatments for OAB rely on antagonism of the $\mathrm{M}_{3}$ receptor in the bladder detrusor muscle to ameliorate detrusor overactivity, which is part of the etiology of OAB. However, AEs may arise as a result of the action of these drugs on muscarinic receptors located throughout the body. Constipation is one such side effect that is commonly reported in association with antimuscarinic treatment and most likely manifests due to antagonism of muscarinic receptors in the gut. Different incidence rates for constipation have been reported in published material on oral antimuscarinic treatments. ${ }^{34}$ However, the incidence of constipation with placebo also varies between studies; when adjusting for the differences in placebo rates, the odds ratios for constipation seen on active treatments ranged from 1.3 to 3.0 (oxybutynin and solifenacin, respectively) compared with placebo, ${ }^{34}$ with higher frequency seen with higher doses of individual compounds. ${ }^{11,33}$ In pooled Phase III studies for darifenacin, the observed rates of constipation were between 2.39 and 3.4 times the placebo rate, for the low $(7.5 \mathrm{mg})$ and high $(15 \mathrm{mg})$ doses, respectively. ${ }^{11}$

Focusing on the pooled Phase III data, the proportion of patients with constipation who discontinued treatment in the darifenacin dose groups was numerically similar to placebo (4\%, 5.6\%, and 4.2\% for darifenacin $7.5 \mathrm{mg}, 15 \mathrm{mg}$, and placebo, respectively). This low rate of discontinuation due to constipation seen in the darifenacin studies may indicate that patients did not perceive their symptoms to be particularly bothersome.

Furthermore, the overall use of laxatives in these studies could be considered low across treatment groups $(5.9 \%$ and $9.5 \%$ for darifenacin $7.5 \mathrm{mg} /$ day and $15 \mathrm{mg}$ /day, respectively, compared with $6.1 \%$ for placebo). Only a slight increase in the use of laxatives in patients reporting constipation as an AE compared with those not reporting constipation was noted $(3.3 \%, 6.6 \%$, and $1.5 \%$ in patients on darifenacin $7.5 \mathrm{mg}, 15 \mathrm{mg}$, and placebo respectively, compared with $2.7 \%, 3.0 \%$, and $3.1 \%$, respectively). These results support the observation that most reported occurrences of constipation were mild in severity. In addition, patients in the pooled Phase III studies experiencing constipation (ie, with recorded symptoms of constipation) did not differ from those without constipation (ie, no recorded incidences of constipation) in terms of satisfaction with treatment, willingness to re-use drug, or preference for the received medication compared with previous OAB therapy. The observation that constipation occurring during darifenacin treatment has only limited impact on patients' experience is further supported by observations from the long-term use of darifenacin.
Patient-reported bowel symptoms, such as constipation, did not change substantially in the 2-year extension study, compared with short-term (12-week) treatment. ${ }^{42}$

This long-term study ${ }^{42}$ and a study in patients with OAB aged $\geq 65$ years $^{46}$ both utilized bowel habit questionnaires. Results of the questionnaire in older patients (as presented in Figure 4B) showed no significant deterioration in bowel habit parameters compared with placebo, despite constipation being reported at a comparable rate to that seen in other darifenacin studies. These results were in line with those observed for bowel habits of the patient population in the 2-year long-term extension study. ${ }^{42}$ Therefore, the symptoms described by patients may have been reported as constipation but the changes in bowel habits may not have been significant nor seen as bothersome in many cases. This may indicate that the procedures for reporting AEs in clinical trials could lead to the incidence of constipation with darifenacin being overstated. Patients who report a reduction in bowel movements may be categorized under the standard term constipation, although the level of bother experienced by the individual patient may not be sufficient to necessitate a clinical diagnosis of constipation.

In general, trials in $\mathrm{OAB}$ have concentrated on clinical outcomes such as the proportion of patients experiencing a particular AE. However, other parameters such as patientreported outcomes may offer a truer picture of the impact of a drug's tolerability and the impact on the patient. In the pooled analysis of Phase III studies, those patients who experienced constipation reported levels of satisfaction and willingness to re-use darifenacin similar or even more positive than those who did not report constipation symptoms.

Although this type of analysis is useful for generating hypotheses and providing large patient numbers, there are limitations to both the analysis and the original studies. In the current analysis the small patient numbers in some subsets should be taken into account when interpreting the data. It should also be noted that although the original studies provide data on constipation they were not designed to address the question on the impact of constipation on patients. Furthermore, in the original studies, the grouping of several different COSTART terms as constipation may also be a contributing factor to relatively high rates of AEs being reported. The incidence rates may have been lower if the more stringent Rome III criteria (Rome Foundation Inc, Raleigh, NC) had been used, as this would have required a specific combination of symptoms to be present to permit a diagnosis of constipation. ${ }^{29}$ The Rome III diagnostic criteria for functional constipation are: loose stools are rarely present without the use of laxatives 
with insufficient criteria for irritable bowel syndrome; plus two or more of the following: fewer than three defecations per week; straining, lumpy or hard stools in at least $25 \%$ of defecations, sensation of incomplete evacuation in at least $25 \%$ of defecations, sensation of anorectal obstruction/blockage in at least $25 \%$ of defecations, or manual maneuvers to facilitate defecation (eg, digital evacuation, support of the pelvic floor) in at least $25 \%$ of defecations. ${ }^{49}$ These criteria must be fulfilled for the last 3 months with symptom onset and at least 6 months prior to diagnosis.

In conclusion, the data reviewed here from published Phase III and Phase IV darifenacin clinical studies indicate that although constipation associated with darifenacin use was a common occurrence, it is principally a tolerability issue with the vast majority of cases reported as mild or moderate in severity. Few patients discontinued treatment due to constipation and overall, patients who reported constipation tended to have the same overall satisfaction with darifenacin treatment as patients who did not report constipation as an AE. Therefore, constipation should not be a main factor influencing the use of darifenacin for treatment of OAB.

\section{Acknowledgments}

Funding for editorial support, drafting, and revising the manuscript by ACUMED ${ }^{\circledR}$ and for the analysis was provided by Novartis Pharma AG. The authors thank Jackie Thirlwell (statistician at Novartis) for her input into data analysis and Jonathon Gibbs (professional writer with ACUMED ${ }^{\circledR}$ ) for his editorial assistance in drafting and revising this manuscript.

\section{Disclosure}

JT declares he received no payment for this work and has no conflicts of interest, equity holding, or interest in the drug. JT has acted as an advisor to Addex Pharma, Almirall, Aryx, AstraZeneca, Danone, Ipsen, Menarini, Movetis, Novartis, Nycomed, Ocera, Rose Pharma, SK Life Sciences, Theravance, Tranzyme, Xenoport, and Zeria. JT has conducted clinical research for Addex Pharma, AstraZeneca, Ipsen, Menarini, Movetis, Novartis, Ocera, Rose Pharma, and Zeria. JT qualifies for authorship under the International Committee of Medical Journal Editors (ICMJE) requirements. JJW declares he received no payment for this work and has no conflicts of interest, equity holding, or interest in the drug. JJW has served as an advisor for Pfizer, Eli Lilly, Novartis, and has conducted clinical research for Astellas, Pfizer, GSK, Novartis, Esteril, Allergan, Schwarz, Jansen-Cilag, Esteve, Yamanouchi, Parexel, Glaxo, PPD, Roche, Fabre, Schering, and Pharmacia. He qualifies for authorship under the ICMJE requirements. GL is an employee of Novartis. GL qualifies for authorship under the ICMJE requirements. ME was an employee of Novartis until January 2010. ME qualifies for authorship under the ICMJE requirements.

\section{References}

1. Haylen BT, de Ridder D, Freeman RM, et al. An International Urogynecological Association (IUGA)/International Continence Society (ICS) joint report on the terminology for female pelvic floor dysfunction. Int Urogynecol J. 2010;21(1):5-26.

2. Irwin DE, Milsom I, Hunskaar S, et al. Population-based survey of urinary incontinence, overactive bladder, and other lower urinary tract symptoms in five countries: results of the EPIC study. Eur Urol. 2006;50(6):1306-1314.

3. Abrams P, Kelleher CJ, Kerr LA, Rogers RG. Overactive bladder significantly affects quality of life. Am J Manag Care. 2000;6(Suppl 11): S580-S590.

4. Tubaro A. Defining overactive bladder: epidemiology and burden of disease. Urology. 2004;64(6 Suppl 1):2-6.

5. Milsom I, Abrams P, Cardozo L, Roberts RG, Thüroff J, Wein AJ. How widespread are the symptoms of an overactive bladder and how are they managed? A population-based prevalence study. BJU Int. 2001;87(9):760-766.

6. Hu TW, WagnerTH, Bentkover JD, et al. Estimated economic costs of overactive bladder in the United States. Urology. 2003;61(6):1123-1128.

7. Reeves $\mathrm{P}$, Irwin D, Kelleher $\mathrm{C}$, et al. The current and future burden and cost of overactive bladder in five European countries. Eur Urol. 2006;50(5):1050-1057.

8. Herbison P, Hay-Smith J, Ellis G, Moore K. Effectiveness of anticholinergic drugs compared to placebo in the treatment of overactive bladder: systematic review. BMJ. 2003;326(7394):841-847.

9. Chapple C, Khullar V, Gabriel Z, Dooley JA. The effects of antimuscarinic treatments in overactive bladder: a systematic review and meta-analysis. Eur Urol. 2005;48(1):5-26.

10. Chapple CR, Khullar V, Gabriel Z, Muston D, Bitoun CE, Weinstein D. The effects of antimuscarinic treatments in overactive bladder: an update of a systematic review and meta-analysis. Eur Urol. 2008;54(3): 543-562.

11. Chapple C, Steers W, Norton P, et al. A pooled analysis of three Phase III studies to investigate the efficacy, tolerability and safety of darifenacin, a muscarinic $\mathrm{M} 3$ selective receptor antagonist, in the treatment of overactive bladder. BJU Int. 2005;95(7):993-1001.

12. Chapple CR. Solifenacin provides effective antimuscarinic therapy for the complete management of overactive bladder. Expert Opin Pharmacother. 2006;7(17):2421-2434.

13. Khullar V, Rovner ES, Dmochowski R, Nitti V, Wang J, Guan Z. Fesoterodine dose response in subjects with overactive bladder syndrome. Urology. 2008;71(5):839-843.

14. Steers W, Corcos J, Foote J, Kralidis G. An investigation of dose titration with darifenacin, an M3-selective receptor antagonist. BJU Int. 2005;95(4):580-586.

15. Dmochowski RR, Larson-Peters A, Aronstein WS, Seifu Y. Efficacy of darifenacin in patients with varying baseline symptom severity. Uro Today Int J. 2009;2(3): doi:10.3834/uij.1944-5784.2009.06.16.

16. Napier C, Gupta P. Darifenacin is selective for the human recombinant M3 receptor subtype. International Continence Society [web page on the internet]. Abstract 445 (August 2002). Available from http://www. icsoffice.org/Abstracts/AbstractsSearch.aspx?EventID=40.

17. Ohtake A, Saitoh C, Yuyama H, et al. Pharmacological characterization of a new antimuscarinic agent, solifenacin succinate, in comparison with other antimuscarinic agents. Biol Pharm Bull. 2007;30(1):54-58.

18. Andersson KE. Potential benefits of muscarinic M3 receptor selectivity. Eur Urol. 2002;Suppl 1:23-28.

19. Abrams P, Andersson KE, Buccafusco JJ, et al. Muscarinic receptors: their distribution and function in body systems, and the implications for treating overactive bladder. Br J Pharmacol. 2006;148(5):565-578. 
20. Abrams P, Wein A. The Overactive Bladder: A Widespread but Treatable Condition. Stockholm, Sweden: Erik Sparre Medical AB; 1998.

21. Braverman AS, Luthin GR, Ruggieri MR. $M_{2}$ muscarinic receptor contributes to contraction of the denervated rat urinary bladder. Am J Physiol. 1998;275(5 Pt 2):R1654-R1660.

22. Gómez A, Martos F, Bellido I, et al. Muscarinic receptor subtypes in human and rat colon smooth muscle. Biochem Pharmacol. 1992;43(11): 2413-2419.

23. Kerr PM, Hillier K, Wallis RM, Garland CJ. Characterization of muscarinic receptors mediating contractions of circular and longitudinal muscle of human isolated colon. Br J Pharmacol. 1995;115(8):1518-1524.

24. Chiba T, Bharucha AE, Thomforde GM, Kost LJ, Phillips SF. Model of rapid gastrointestinal transit in dogs: effects of muscarinic antagonists and a nitric oxide synthase inhibitor. Neurogastroenterol Motil. 2002;14(5):535-541.

25. Li M, Johnson CP, Adams MB, Sarna SK. Cholinergic and nitrergic regulation of in vivo giant migrating contractions in rat colon. $\mathrm{Am} \mathrm{J}$ Physiol Gastrointest Liver Physiol. 2002;283(3):G544-G552.

26. Matsui M, Motomura D, Fujikawa T, et al. Mice lacking M3 and M3 muscarinic acetylcholine receptors are devoid of cholinergic smooth muscle contractions but still viable. J Neurosci. 2002;22(24):10627-10632.

27. Matsui M, Motomura D, Karasawa $\mathrm{H}$, et al. Multiple functional defects in peripheral autonomic organs in mice lacking muscarinic acetylcholine receptor gene for the M3 subtype. Proc Natl Acad Sci U S A 2000;97(17):9579-9584.

28. Longstreth GF, Thompson WG, Chey WD, Houghton LA, Mearin F, Spiller RC. Functional bowel disorders. Gastroenterology. 2006;130(5): 1480-1491.

29. Choung RS, Locke GR III, Schleck GR, Zinsmeister AR, Talley NJ. Cumulative incidence of chronic constipation: a population-based study 1988-2003. Aliment Pharmacol Ther. 2007;26(11-12):1521-1528.

30. Armstrong RB, Dmochowski RR, Sand PK, Macdiarmid S. Safety and tolerability of extended-release oxybutynin once daily in urinary incontinence: combined results from two Phase 4 controlled clinical trials. Int Urol Nephrol. 2007;39(4):1069-1077.

31. Elinoff V, Bavendam T, Glasser DB, Carlsson M, Eyland N, Roberts R. Symptom-specific efficacy of tolterodine extended release in patients with overactive bladder: the IMPACT trial. Int J Clin Pract. 2006;60(6):745-751.

32. Chapple CR, Cardozo L, Steers WD, Govier FE. Solifenacin significantly improves all symptoms of overactive bladder syndrome. Int $J$ Clin Pract. 2006;60(8):959-966.

33. Van Kerrebroeck P, Kreder K, Jonas U, Zinner N, Wein A; Tolterodine Study Group. Tolterodine once-daily: superior efficacy and tolerability in the treatment of the overactive bladder. Urology. 2001;57(3):414-421.

34. Meek PD, Evang SD, Tadrous M, Roux-Lirange D, Triller DM, Gumustop B. Overactive bladder drugs and constipation: a meta-analysis of randomized, placebo-controlled trials. Dig Dis Sci. 2011;56(1):7-18.

35. Dmochowski RR, Nitti V, Staskin D, Luber K, Appell R, Davila GW. Transdermal oxybutynin in the treatment of adults with overactive bladder: combined results of two randomized clinical trials. World $J$ Urol. 2005;23(4):263-270.

36. Abrams P, Swift S. Solifenacin is effective for the treatment of OAB dry patients: a pooled analysis. Eur Urol. 2005;48(3):483-487.
37. Chapple CR, Rechberger T, Al-Shukri S, et al. Randomized, double-blind placebo- and tolterodine-controlled trial of the once-daily antimuscarinic agent solifenacin in patients with symptomatic overactive bladder. $B J U$ Int. 2004;93(3):303-310.

38. Staskin D, Sand P, Zinner N, Dmochowski R; Trospium Study Group. Once daily trospium chloride is effective and well tolerated for the treatment of overactive bladder: results from a multicenter Phase III trial. J Urol. 2007;178(3 Pt 1):978-983.

39. Foote J, Elhilali M; Darifenacin Study Group. A multicenter, randomized, double-blind study of darifenacin versus tolterodine in the treatment of overactive bladder (OAB). In: British Geriatrics Society. Communications to the Autumn Meeting of the British Geriatrics Society: Programme of Abstracts. Poster presented at the British Geriatrics Society Annual Meeting, Harrogate, UK, October 6-8, 2004, Poster 56. Available from: http://www.bgs.org.uk/PDF\%20Downloads/ Abstracts\%20Autumn2004.pdf. Accessed January 20, 2012.

40. Hill S, Khullar V, Wyndaele JJ, Lheritier K; Darifenacin Study Group. Dose response with darifenacin, a novel once-daily M3 selective receptor antagonist for the treatment of overactive bladder: results of a fixed dose study. Int Urogynecol J Pelvic Floor Dysfunct. 2006;17(3):239-247.

41. Haab F, Stewart L, Dwyer P. Darifenacin, an M3 selective receptor antagonist, is an effective and well-tolerated once-daily treatment for overactive bladder. Eur Urol. 2004;45(4):420-429.

42. Haab F, Corcos J, Siami P, et al. Long-term treatment with darifenacin for overactive bladder: results of a 2-year, open-label extension study. BJU Int. 2006;98(5):1025-1032.

43. Zinner N, Kobashi KC, Ebinger U, et al. Darifenacin treatment for overactive bladder in patients who expressed dissatisfaction with prior extended-release antimuscarinic therapy. Int J Clin Pract. 2008;62(11):1664-1674.

44. Chancellor MB, Kianifard F, Beamer E, et al. A comparison of the efficacy of darifenacin alone vs darifenacin plus a Behavioural Modification Programme upon the symptoms of overactive bladder. Int $J$ Clin Pract. 2008;62(4):606-613.

45. Zinner N, Susset J, Gittelman M, Arguinzoniz M, Rekeda L, Haab F. Efficacy, tolerability and safety of darifenacin, an M3 selective receptor antagonist: an investigation of warning time in patients with $\mathrm{OAB}$. Int J Clin Pract. 2006;60(1):119-126.

46. Chapple C, DuBeau C, Ebinger U, Rekeda L, Viegas A. Darifenacin treatment of patients $\geq 65$ years with overactive bladder: results of a randomized, controlled, 12-week trial. Curr Med Res Opin. 2007; 23(10):2347-2358.

47. Chow S-C, Liu J-P. Chapter 13: Safety assessment. In: Design and Analysis of Clinical Trials: Concepts and Methodologies. 2nd ed. Hoboken, New Jersey, US; John Wiley \& Sons Inc: 2004.

48. Foote J, Glavind K, Kralidis G, Wyndaele JJ. Treatment of overactive bladder in the older patient: pooled analysis of three Phase III studies of darifenacin, an M3 selective receptor antagonist. Eur Urol. 2005;48(3):471-477.

49. Longstreth GF, Thompson WG, Chey WD, Houghton LA, Mearin F, Spiller RC. Functional bowel disorders. Gastroenterology. 2006;130(5): 1480-1491.

Drug, Healthcare and Patient Safety

\section{Publish your work in this journal}

Drug, Healthcare and Patient Safety is an international, peer-reviewed open-access journal exploring patient safety issues in the healthcare continuum from diagnostic and screening interventions through to treatment, drug therapy and surgery. The journal is characterized by the rapid reporting of reviews, original research, clinical, epidemiological and

post-marketing surveillance studies, risk management, health literacy and educational programs across all areas of healthcare delivery. The manuscript management system is completely online and includes a very quick and fair peer-review system. Visit http://www.dovepress.com/ testimonials.php to read real quotes from published authors. 